\title{
I leocecal intussusception due to the intestinal metastasis of malignant melanoma
}

\author{
S. Erpulat OZI S ${ }^{1}$, G. Kaan ATAC ${ }^{2}$, Zafer SAHLI ${ }^{1}$, Egemen Akincioglu ${ }^{3}$ \\ 1. Department of Surgery, Ufuk University Medical School, Ankara, Turkey. 2. Department of Radiology, Ufuk University \\ Medical School, Ankara, Turkey. 3. Department of Pathology, Ufuk University Medical School, Ankara, Turkey.
}

Correspondence: Salih Erpulat OZIS. Address: Department of Surgery, Ufuk University Medical School, Konya Yolu No: 86-88 06510, Balgat-Ankara, Turkey. E-mail: erpulat@yahoo.com

Received: April 11, 2014

DOI : $10.5430 /$ crcp.v2n1p1

Accepted: July 11, 2014

Online Published: August 29, 2014

\begin{abstract}
Intestinal obstruction due to ileocecal intussusception is very rare in adult age. Primary and secondary tumors, inflammatory or proliferative processes of the bowel are the causative factors. Malignant melanoma is a common disease in the western world with high metastatic rates, and is also a common extra-abdominal source of gastrointestinal metastases.

We present a 55-year-old woman with the complaints of an abrupt colicky abdominal pain, nausea and vomiting. Her history revealed cutaneous melanoma that was excised five years ago. Her physical examination revealed abdominal distention with generalized abdominal tenderness. Multidetector computed tomography (MDCT) revealed a mass at ileocecal junction with dilatation of entire small bowel segments. Metastasis was confirmed by laparotomy. After a right-sided hemicolectomy, patient died of disease with widespread metastasis with of one year after colectomy.
\end{abstract}

\section{Key words}

Malignant melanoma, Intestinal metastasis, Intussusception

\section{I ntroduction}

Intussusception, telescoping of an intestinal segment into the lumen of adjacent intestinal segment, is a rare condition in adulthood and accounts for $5 \%$ of total incidents of intussusception ${ }^{[1]}$. Despite its classical triad of colicky abdominal pain, bloody stools and palpable tender mass in childhood, the presentation in adult ages is nonspecific and variable. Also the intussusceptions in adulthood are generally secondary to an organic lesion on the contrary to the common idiopathic form in childhood. These lesions, either benign or malignant, act as leading points and cause telescoping of proximal intestinal segments into the distal lumen in direction of peristalsis.

Malign melanoma which is well known skin tumor, are becoming more prevalent in Western World. Cutaneous melanoma can spread every part of the body but it is the most prevalent metastatic lesion of the bowel ${ }^{[2]}$. Even thouh it spreads distant parts of the bowel, it is unusual to discover metastatic melanoma with clinical signs and symptoms. These silent metastases are generally diagnosed during autopsy, only $5 \%$ of the metastatic lesions in bowel are diagnosed clinically ${ }^{[3]}$. 
We hereby present a case of an ileocecal intussusception due to intestinal metastasis of malignant melanoma in an adult patient. The prompt intervention to the combination of these rare conditions not only enhances survival but also improve quality of life.

\section{Case presentation}

A 55-year-old woman with complaints of abrupt colicky abdominal pain, nausea and vomiting was admitted to the ER. She had a history of cutaneous melanoma which was excised from the neck five years ago. Stage and margin status of cutaneous melanoma was not available. She has followed up uneventfully since then. Her physical examination revealed abdominal distention with generalized tenderness. Her blood tests were unremarkable except mild anemia. In ER evaluation, a mass at the right lower quadrant was suspected, and a multidetector computed tomography (MDCT) was performed. Axial and coronal reformatted images showed intussusception of distal ileum into the cecum containing $5 \mathrm{~cm} \times$ $4 \mathrm{~cm}$ solid mass with contrast enhancement. MDCT also showed that fat tissue stranding and edema, along with peritumoral nodules. The diameter of this nodules are smaller than two centimeters in diameter and they are compatible with lymph nodes. No mass lesion indicating metastasis to the other intraabdominal tissues or free peritoneal fluid was noticed. Even though oral iodinated contrast was passed into the colonic lumen, but small bowel segments were distended (see Figure 1a, 1b).
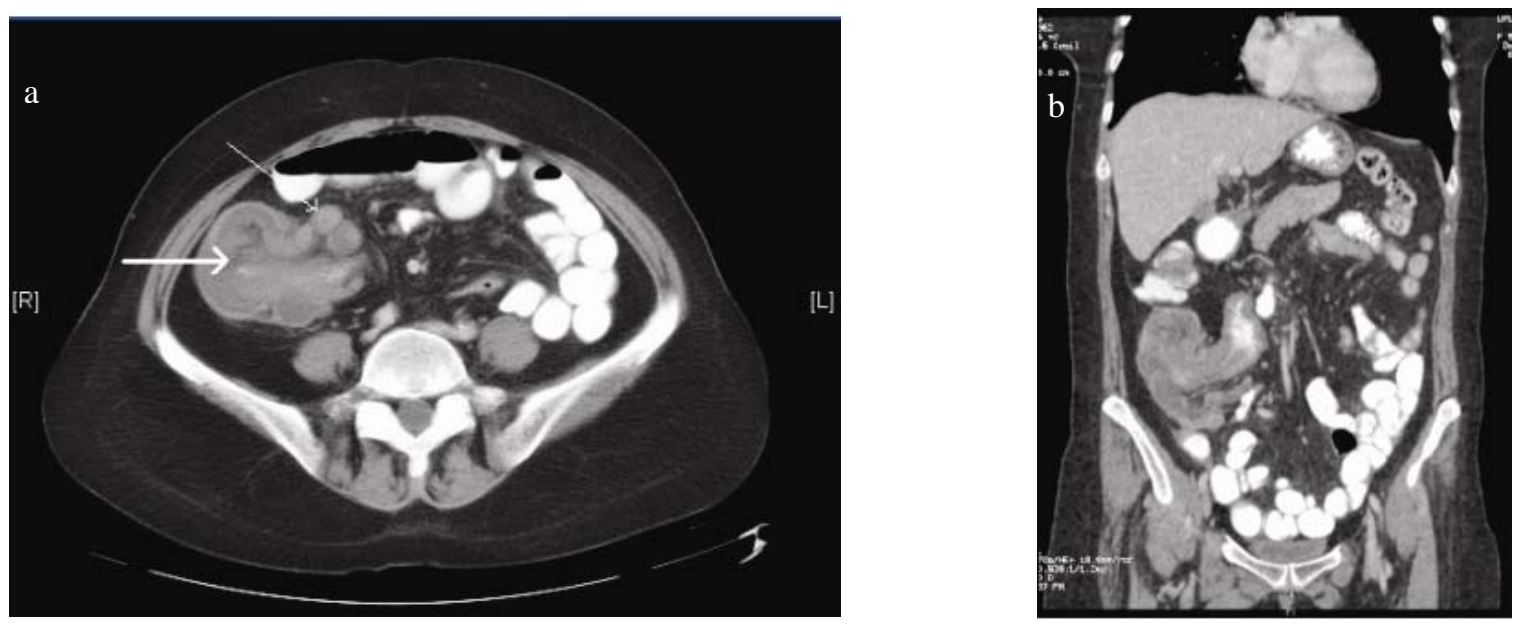

Figure 1. a: Axial CT image through the umbilicus shows intracecal concentric bowel mass with surrounding fat tissue (thick white arrow) and peritumoral edema, stranding and circular small masses compatible with lypmhadenopathies (thin white arrow). b: Coronal reformatted view of the torso shows orientation of the ileocecal mass and filling of the cecal lumen with it.

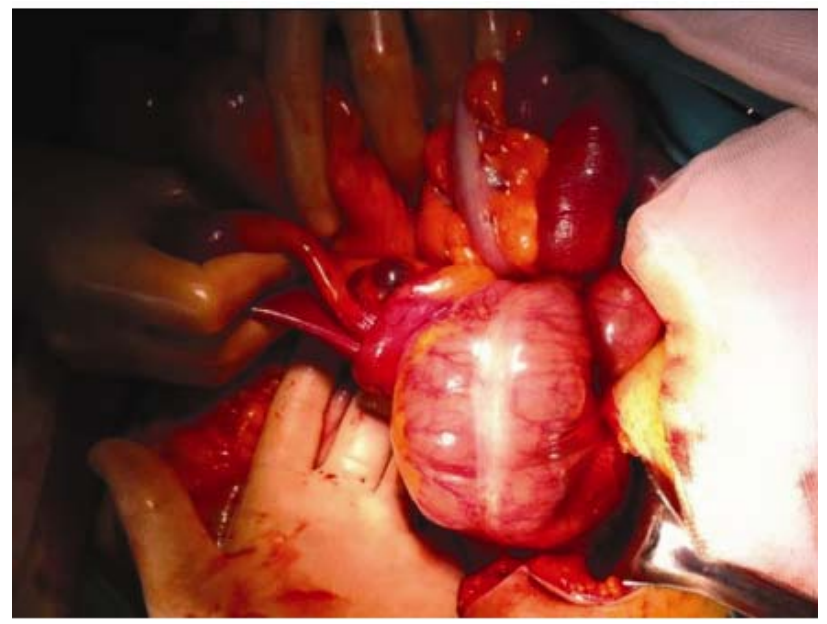

Figure 2. Perioperative finding of intussusception 
She was operated on the emergency basis at that night and right hemicolectomy without manual reduction was performed (see Figure 2). No clue of peritoneal or soft tissue metastasis was observed. She recovered in a week and discharged without medical problems.

In macroscopical examination: $5 \mathrm{~cm} \times 5 \mathrm{~cm} \times 1.5 \mathrm{~cm}$ sized, polypoid-shaped, a black colored ulcerated tumor was observed on the mucosal surface of the colon. Tumor was $6 \mathrm{~cm}$ away from proximal, $7 \mathrm{~cm}$ from distal and, $0.3 \mathrm{~cm}$ from serosal margins. Histological evaluation of these mass revealed a malignant tumoral infiltration of colonic wall. Tumor is composed of solid nests arranged in cords (see Figure 3a). No necrosis is visible. Black pigment which is compatible with melanin is present in extensively (see Figure 3b). Nuclei of tumor cells are pleomorphic, nucleoli are prominent and chromatin distribution is vesicular. Mitotic activity is frequent. Tumor was also infiltrated muscularis propria and serosal surface. Lymphovascular and perineural invasion were also seen. No metastasis was detected in thirteen dissected mesenteric lymph nodes. Tumor cells were positive for HMB-45 (CellMarQ, 1/50 dilution), S-100 (clone 4c49, CellMarQ, 1/200 dilution) and Melan-A (clone A103, Neomarkers, 1/200 dilution) immunostain (see Figure 4a, b, c). Together with clinical history, histological, immunohistochemical findings, we interpretated the case as metastatic malignant melanoma of colon, intussusception is probably caused with malign melanoma metastasis.

Follow up: Even though recovery period was uneventful, we were informed that, patient died of disease with widespread metastasis with of one year after colectomy.

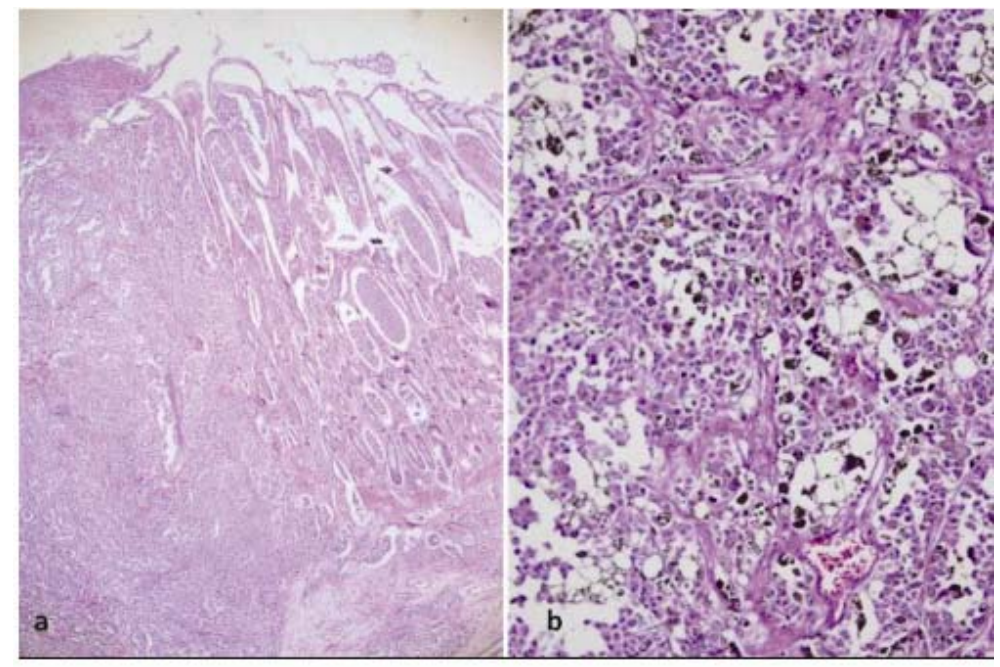

Figure 3. a: Realtionship between tumor and large bowel mucosa. H\&E, $\times 40$; b: Tumor cells with melanin pigment. H\&E, $\times 200$

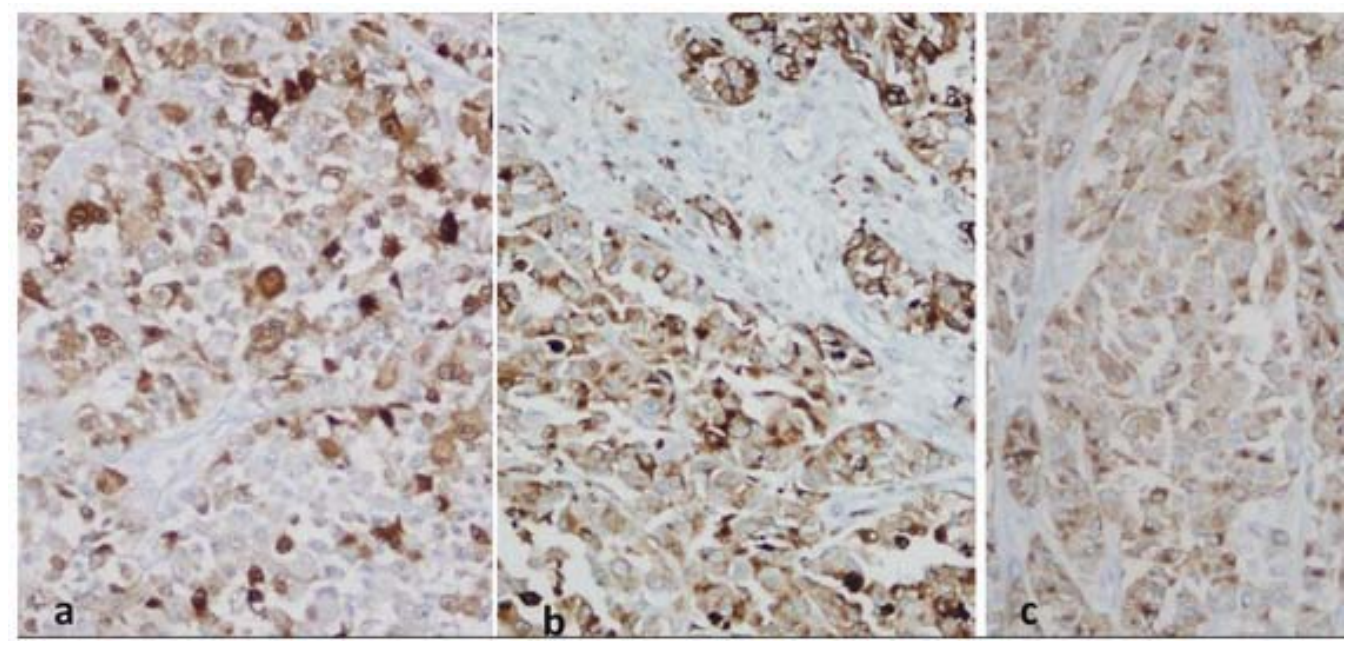

Figure 4. a: S-100, ×400; b: HMB-45, ×400; c: Melan-A, $\times 400$ 


\section{Discussion}

Patient in current case was diagnosed with intussusception leading to intestinal obstruction. Intussusception is the leading cause of intestinal obstruction in childhood, it accounts for only 5\% of intestinal obstructions in adulthood. Only one fourth to one third of the patients with intussusception was found to be presented with acute obstructive symptoms ${ }^{[4,5]}$.

Despite high sensitivity and specificity of ultrasound while evaluating intussusception in childhood, the massive gas in the dilated bowel loops proximal to the obstructed site is troublesome for the radiologist and the accuracy of ultrasound is about $60 \%$ in adulthood intussusceptions ${ }^{[5]}$. In case of intestinal obstruction, not only the location of the lesion but also the extension of the disease can be evaluated by conventional barium studies, enteroclysis or computed tomography (CT). Especially for CT, evaluation of the axial and coronal reformatted images together increases the efficacy of technique and help to delineate the exact localization of obstruction. Intestinal iodine containing liquid material fills the intestinal lumen and may pass through the narrowed part and reach to the distal colonic segments against the obstructive sign and complaints. Enlarged mesenteric lymph nodes may contain metastatic cells in addition to the local invasion ${ }^{[6,7]}$. Moreover additional information like viability of the intestinal wall, patency of the intestinal lumen can be obtained by CT.

In $90 \%$ of the patients, the intussusceptions are secondary to an organic lesion like tumors, intestinal diverticuli, and polyps ${ }^{[1]}$. As a great majority of these lesions are related to malignancy in elderly, the treatment of choice is surgery. Reduction prior to surgery is an issue of debate. The theoretical risks like luminal seeding or venous embolization of a tumor, perforation during manipulation, preclude clinicians from manual reduction.

Clear cell sarcoma is a concern in differantial diagnosis histologically and immunohistochemically may resemble malign melanoma. However melanin pigmentation may not be visible on histologic section. Whereas osteoclast like multinucleer giant cells are prominent in clear cell sarcoma, these cells are not a common finding in malign melanoma. Immunohistochemical features are similar in both tumors. $t(12 ; 22)$ have been reported in clear cell sarcoma and may be of help discriminating these entities. Clear cell sarcoma was redefined as clear cell sarcoma-like tumor of the gastrointestinal tract in 2003. Nevertheless immunohistochemical profile of this lesion differs from malign melanom. HMB-45 and MelanA expressions favor malignant melanoma. In addition to histological and immunohistochemical findings, clinical presentation of current case supports malignant melanoma diagnosis ${ }^{[8,9]}$. Since patient is known to have a cutaneous malignant melanoma five year prior to current right hemicolectomy.

Metastasis of malignant melanoma to the gastrointestinal (GI) tract is even though common, it remains clinically silent. It may occur very lately after resection of primary cutaneous tumor. More than $50 \%$ of the melanoma patients with GI metastasis are diagnosed during autopsy. In a review of 385 patients by Panagiotou et al, only $4.7 \%$ of the patients were diagnosed having GI involvement ${ }^{[10]}$. The metastasis is found to be at the small bowel and mesentery in $61.1 \%$, and at the colon and rectum in $22.2 \%{ }^{[10]}$. They were diagnosed by using endoscopy, upper GI barium series, barium enema or abdominal CT. In case of a history of malignant melanoma, some authors recommend magnetic resonance imaging (MRI) as it depicts the location and nature of the melanotic foci due to signal changes whereas the others propose positron emission tomography (PET)-CT due to the high metabolic consumption of 18 fluoroglucose that helps to locate the lesions ${ }^{[11,12]}$. Surgery is treatment of choice in case of metastases as the surgical resection not only enhances survival but also improves quality of life ${ }^{[10,13]}$.

We presented a rare case of melanotic intestinal metastasis to the distal part of small bowel that causes telescoping of the terminal ileum into the ascending colon. As it is a fast, efficient, and relatively available modality, we performed a MDCT that revealed a mass at ileocecal junction with dilation of entire small bowel segments. In case of acute abdominal symptoms, a positive history for malignant melanoma should alert the physician since it commonly spreads to bowel. The prompt intervention not only enhances survival but also improve quality of life. 


\section{References}

[1] Marinis A, Yiallourou A, Samanides L, Dafnios N, Anastasopoulos G, Vassiliou I, et al. Intussusception of the bowel in adults: a review. World J Gastroenterol. 2009 Jan 28; 15(4): 407-11. PMid: 19152443. http://dx.doi.org/10.3748/wjg.15.407

[2] Mucci T, Long W, Witkiewicz A, Mastrangelo MJ, Rosato EL, Berger AC. Metastatic melanoma causing jejunal intussusception. J Gastrointest Surg. 2007Dec; 11(12): 1755-7. PMid: 17619936. http://dx.doi.org/10.1007/s11605-007-0215-y

[3] Resta G, Anania G, Messina F, De Tullio D, Ferrocci G, Zanzi F, et al. Jejuno-jejunal invagination due to intestinal melanoma. World J Gastroenterol. 2007 Jan 14; 13(2): 310-2. PMid: 17226915. http://dx.doi.org/10.3748/wjg.v13.i2.310

[4] Barussaud M, Regenet N, Briennon X, de Kerviler B, Pessaux P, Kohneh-Sharhi N, et al. Clinical spectrum and surgical approach of adult intussusceptions: a multicentric study. Int J Colorectal Dis. 2006 Dec; 21(8): 834-9. PMid: 15951987. http://dx.doi.org/10.1007/s00384-005-0789-3

[5] Wang N, Cui XY, Liu Y, Long J, Xu YH, Guo RX, et al. Adult intussusception: a retrospective review of 41 cases. World J Gastroenterol. 2009 Jul 14; 15(26): 3303-8. PMid: 19598308. http://dx.doi.org/10.3748/wjg.15.3303

[6] A Filippone A, Cianci R, Grassedonie, et al. Four-detector computed tomographic imaging of small bowel obstruction: usefulness of axial and coronal plane combined reading. J ComputTomogr Imaging. 2007; 31: 499-507.

[7] O’Regan K, Bogue CO, Corrigan M, et al. CT imaging of metastatic malignant melanoma. Contemporary Diagnostic Radiology 2008; 31: 1-6. http://dx.doi.org/10.1097/01.CDR.0000334536.65603.95

[8] Lyle PL, Amato CM, Fitzpatrick JE, Robinson WA. Gastrointestinal melanoma or clear cell sarcoma? Molecular evaluation of 7 cases previously diagnosed as malignant melanoma. Am J Surg Pathol. 2008 Jun; 32(6): 858-66. PMid: 18408594. http://dx.doi.org/10.1097/PAS.0b013e31815b8288

[9] Thway K, Judson I, Fisher C. Clear cell sarcoma-like tumor of the gastrointestinal tract, presenting as a second malignancy after childhood hepatoblastoma. Case Rep Med. 2014; 2014: 984369. Epub 2014 Feb 17.

[10] Panagiotou I, Brountzos EN, Bafaloukos D, Stoupis C, Brestas P, Kelekis DA. Malignant melanoma metastatic to the gastrointestinal tract. Melanoma Res. 2002 Apr; 12(2): 169-73. PMid: 11930114. http://dx.doi.org/10.1097/00008390-200204000-00010

[11] Strobel K, Skalsky J, Hany TF, et al. Small bowel invagination caused by melanoma metastasis. ClinNuc Med. 2007 ; 32: $213-214$. PMid: 17314600. http://dx.doi.org/10.1097/01.rlu.0000255212.17086.e9

[12] Tatlidil R, Mandelkern M. Melanoma Research. FDG-PET in the detection of gastrointestinal metastases in melanoma. 2001; 11: 297-301.

[13] Gutman H, Hess KR, Kokotsakis JA, Ross MI, Guinee VF, Balch CM. Surgery for abdominal metastases of cutaneous melanoma. World J Surg. 2001 Jun; 25(6): 750-8. PMid: 11376411. http://dx.doi.org/10.1007/s00268-001-0027-2 